\title{
Evaluation of the Parameters that Affect the Cost of Laparoscopic Sleeve Gastrectomy
}

\author{
Abdullah Şişik (1) \\ Department of General Surgery, University of Health Sciences Ümraniye Training and Research Hospital, İstanbul, Turkey
}

Cite this article as: Şişik A. Evaluation of the Parameters that Affect the Cost of Laparoscopic Sleeve Gastrectomy. JAREM 2018; 8(2): 96-100.

\begin{abstract}
Objective: Laparoscopic sleeve gastrectomy (LSG) is an easy and safe surgical procedure with effective results. The cost of LSG surgery is influenced by many parameters including the medical supplies used. Aim of this study was determining the parameters affecting the cost of this procedure and whether it is a cost-effective procedure for hospitals.

Methods: Laparoscopic sleeve gastrectomy performed in a public hospital during 2016 were retrospectively reviewed. Parameters such as age, sex, body mass index, the length of hospitalization, the postoperative need for a follow-up in an intensive care unit (ICU), and the presence of complications were determined. In addition, all expensive items incurred during LSG procedure, their costs, and the amount of invoicing for the Social Insurance Institution were determined. The patients whose procedural costs and invoiced amounts exceeded 80 percentiles constituted an increased cost and increased billing group, and those under 80 percentile constituted a normal cost and normal billing group. The parameters were compared between the increased and normal groups.

Results: A total of 121 patients ( 10 males and 111 females) were included in the study. The mean age was 38.7 years, and the mean body mass index was $47.6 \mathrm{~kg} / \mathrm{m}^{2}$. There were 95 patients in the normal cost group, 26 in the increased cost group, 96 in the normal billing amount group, and 25 in the increased bill amount group. It was found that seven complicated patients were in the increased bill amount group, and six of seven were also in the increased cost group ( $p=0.001$ ). In the increased bill amount and increased cost groups, the length of hospitalization was $14.3 \pm 19.7$ and $14.4 \pm 19.7$ days, respectively $(p=0.001)$. There was no significant difference between the groups in terms of age, sex, body mass index, and ICU need ( $p>0.05)$.

Conclusion: The development of complications after LSG and the increased length of hospitalization increase the procedural cost. There is no correlation between cost increase and patient variables. Therefore, the factors affecting cost increase should be considered as unpredictable conditions.
\end{abstract}

Keywords: Obesity, laparoscopic sleeve gastrectomy, cost analysis

ORCID ID of the author: A.Ş. 0000-0002-7500-8651.

\section{INTRODUCTION}

Bariatric surgery provides long-term weight loss, reduces the incidence of obesity-related diseases, and improves survival. Surgical treatment results in a 50\% reduction in excess weight (1). Obesity-related diseases may also be treated by bariatric surgery with excess weight loss $(2,3)$. Bariatric procedures work by restriction, malabsorption, and hormonal effects. The mortality rates in bariatric surgery are in the range of $0.3 \%-0.6 \%$ (4). Currently, the most common procedures are laparoscopic sleeve gastrectomy (LSG) and Roux-en-Y gastric bypass $(5,6)$. Bariatric procedures are the most effective method for the treatment of morbid obesity. Patients' gains are further increased by the removal of additional diseases, including Type 2 diabetes, lipid disorders, and hypertension. As a result, the mortality rates due to these comorbid diseases are reduced, and the life span of the patient is prolonged.
In an LSG surgery, which is a bariatric procedure, medical devices (staples, sealing devices, laparoscopic trocars, and laparoscopic hand tools) must be used. Considering that comorbid conditions are more frequently seen in LSG-treated patients, these patients may require a postoperative follow-up in the intensive care unit (ICU). The need for blood product transfusions, percutaneous drainage procedures, stenting procedures, and re-operation interventions may arise in cases wherein complications, including leakage or bleeding, postoperatively develop. All of these can be considered as the parameters that affect procedural cost $(7,8)$.

Hospital administrators cannot determine the fees for services offered in hospitals, which renders them to control expenses. The use of several materials in hospitals will help understand this difficulty. Managers aim to provide quality services at increasing costs by setting new strategies (9). Concepts such as quality, efficiency, and cost should be considered while provid- 
ing health services that are inexpensive, consumer demandbased, and beneficial to the society. $(10,11)$. Many countries have recently made new arrangements for health care costs (12-14). The factors affecting the costs of hospital enterprises are the capacity and capacity utilization of the hospital, technological condition used, the intensity of the population served, the quality of the service, the reputation of the hospital, the number of employees, and financial income source $(13,14)$.

In this study, we aimed to investigate the cost analysis of LSG operations performed in 2016 in a public hospital.

\section{METHODS}

A descriptive study was planned. The study was performed in accordance with the ethical standards of the 1964 Declaration of Helsinki and its later amendments. The STrengthening the Reporting of Observational studies in Epidemiology (STROBE) guidelines were used while reporting this observational study (15).

\section{Patient Selection}

Patients who underwent LSG for obesity between January 2016 and December 2016 were retrospectively analyzed from the hospital registry system. It has been learned that LSG is paid as all-inclusive by Social Insurance Institution (SII) and that some medical supplies can also be separately billed. Patients' demographic characteristics (age, sex, and body mass index [BMI]), the length of hospitalization, and the costs of medical supplies, medications, laboratory, radiological and pathological examinations, and transfused blood products were recorded. Additionally, the amounts billed to SII by the hospital were recorded. The all-inclusive payment made by SII was also recorded. All the amounts were summed and the total cost and total invoice amounts were obtained. "Increased cost" and "increased bill amount" were defined as the main outcome variables. The cost and billing amounts above 80 percentile were defined as "increased" (7). With this method, two groups were formed based on the cost and bill amount, and each of them was also categorized as "increased" or "normal." The age, sex, BMI, the length of hospitalization, the need for a postoperative followup in ICU, and the presence of complications were compared among these groups.

For LSG operations, it was determined that SII made the allinclusive payment that includes the expenses of personnel, medical supplies, medications, laboratory, radiological and pathological examinations, and transfused blood products. The amount of this payment was 3.410 Turkish Liras (TL) per operation. In addition, it was determined that the refunds were separately received by invoicing the staples, sealing devices, and some additional medicines other than the all-inclusive payment. The patients who postoperatively needed a follow-up in the ICU would also be billed for the expenses of medications, laboratory and radiological examinations, and transfused blood products. In our study, the costs of surgical hand tools and retractors used in the surgery, laparoscopic imaging, and insufflation systems were disregarded. Moreover, personnel expenses were not included in the costs because it was not possible to collect the information about personnel expenses from the hospital registry system. Bed charges were also not included in the total cost and bill amount.

According to the average exchange rates of the year 2016, one United States dollar was determined as 3.02 TL.

\section{Statistical Analysis}

Data are expressed as mean \pm standard deviation or number and percentage. The patients with increased or normal cost and invoice amounts were compared using the Student's t-test or Mann-Whitney U-test for continuous variables and using the chi-square or Fischer's exact test for categorical variables. Logistic regression models were used to examine the contribution of other factors such as increased costs. P-values of $<0.05$ were considered statistically significant. Statistical analysis was performed using the Statistical Package for the Social Sciences (SPSS, IBM Comp.; version 20, Armonk, NY, USA).

\section{Table 1. Descriptive statistics of the patients}

\begin{tabular}{|c|c|c|c|c|c|c|}
\hline \multicolumn{7}{|l|}{$n=121$} \\
\hline \multicolumn{7}{|l|}{ Sex } \\
\hline Male & 10 & & & & & \\
\hline \multirow[t]{2}{*}{ Female } & 111 & & & & & \\
\hline & Mean \pm SD & Min-Max & & & & \\
\hline Age & $38.7 \pm 10.8$ & $19-62$ & & & & \\
\hline BMI $\left(\mathrm{kg} / \mathrm{m}^{2}\right)$ & $47.6 \pm 5.6$ & $40-68$ & & & & \\
\hline \multirow[t]{3}{*}{ Length of hospitalization (day) } & $6.9 \pm 10.2$ & $3-71$ & & & & \\
\hline & & & \multicolumn{4}{|c|}{ Percentiles } \\
\hline & & & 25 & 50 & 75 & 80 \\
\hline Total billing amount (TL) & $6095.7 \pm 3586.7$ & 3410.0-28427.6 & 4443.7 & 5408.8 & 6212.8 & 6575.7 \\
\hline Total cost amount (TL) & $3633.5 \pm 3520.3$ & $1424.1-22775.9$ & 2188.8 & 3009.4 & 3965.3 & 4120 \\
\hline
\end{tabular}




\section{RESULTS}

During the study, 121 patients underwent LSG due to obesity. There were 10 males and 111 females. The average age was 38.7 (19-62) years; the mean BMI was 47.6 (40-68); and the mean length of hospitalization was 6.9 (3-71) days. When the total cost and total invoice amounts were examined, the average cost and total invoice were 3633.5 TL and $6095 \mathrm{TL}$, respectively. It was determined that the amount that corresponds to the $80^{\text {th }}$ percentile for the total cost and total billing were 4120 TL and 6575.7 TL, respectively. The patients with a cost above $4120 \mathrm{TL}$ were included in the increased cost group, and those billed above 6575.7 TL were included in the increased bill amount group (Table 1).

Postoperatively, 11 patients were enrolled in ICU. The median duration of stay in the ICU was 2 (2-3) days. Seven patients had complications; four of these had complications such as leakage from the staple line, one had stenosis, and two had intra-abdominal collections wherein a certain leakage were not evaluated (Table 2).

It was observed that there was a difference of approximately 2,420 TL between the cost and billed amount in the standard operation

Table 2. Analysis of the patients who were enrolled in the ICU and who had complications

\begin{tabular}{|l|c|}
\hline Number of patients requiring ICU & 11 \\
\hline Length of ICU (day) (median (min-max)) & $2(2-3)$ \\
\hline Complication & 7 \\
\hline Leakage & 4 \\
\hline Stenosis & 1 \\
\hline Suspect of leakage (intra-abdominal collection) & 2 \\
\hline ICU: Intensive care unit
\end{tabular}

period. Since personnel and bed costs were not included, these expenses were also covered in this amount.

In the analysis of the effect of the parameters on the groups wherein the cost and billing amounts were over 80 percentile, a longer hospital stay and the presence of complication (s) were found to be statistically significant. Age, sex, BMI, and ICU need did not affect the increased billing amount and increased cost (Table 3).

\section{DISCUSSION}

The financial burden of obesity and obesity-related diseases cannot be underestimated. The cost of treating obesity-related diseases, including hypertension, type 2 diabetes mellitus, and cardiovascular system diseases, is very high. This cost negatively affects the society by affecting the gross national product (16, 17). Along with the treatment of obesity, the number of several obesity-related systemic diseases is also decreasing. None of the non-surgical methods involved in the treatment of obesity are as effective as surgical treatment (18). Among the surgical treatment methods, LSG is a procedure with proven efficacy and safety (19). In this study, we aimed to reveal the cost analysis of the LSG procedure and investigated the effects of age, sex, BMI, ICU requirement, and the presence of complication on the increased costs of the procedure. We conclude that the presence of complications and the length of hospitalization are the statistically significant parameters affecting the cost.

Staple line leakages are the most important cause of morbidity after LSG. They can also result into mortality in patients. However, mortality did not occur in our study. Of the seven patients who had complications in the study, four were diagnosed as staple line leakages, whereas two patients were treated as suspects of leakage due to the intra-abdominal collection. When $85 \%$ of the complications are thought to be leakage-related complications, it can be concluded that the most important factor that increases

Table 3. Comparison of groups according to cost and billing amounts

\begin{tabular}{|c|c|c|c|c|c|c|}
\hline & $\begin{array}{l}\text { Normal Billing } \\
\text { Amount }(n=94)\end{array}$ & $\begin{array}{l}\text { Increased Billing } \\
\text { Amount }(n=27)\end{array}$ & p & $\begin{array}{c}\text { Normal Cost } \\
(n=95)\end{array}$ & $\begin{array}{l}\text { Increased Cost } \\
\qquad(n=26)\end{array}$ & $p$ \\
\hline Age & $39.04 \pm 10.9$ & $37.7 \pm 10.6$ & 0.563 & $38.6 \pm 11.4$ & $39.4 \pm 8.7$ & 0.747 \\
\hline \multicolumn{7}{|l|}{ Gender } \\
\hline Male & 8 & 2 & 1 & 87 & 24 & 1 \\
\hline Female & 86 & 25 & & 8 & 2 & \\
\hline BMI $\left(\mathrm{kg} / \mathrm{m}^{2}\right)$ & $47.8 \pm 5.6$ & $47 \pm 5.4$ & 0.509 & $47.9 \pm 5.7$ & $46.4 \pm 4.8$ & 0.215 \\
\hline Length of hosp. stay (day) & $4.84 \pm 2.1$ & $14.3 \pm 19.7$ & 0.001 & $4.9 \pm 2.95$ & $14.4 \pm 19.7$ & 0.001 \\
\hline \multicolumn{7}{|l|}{ ICU requirement } \\
\hline Yes & 6 & 5 & 0.670 & 6 & 5 & \multirow{2}{*}{0.570} \\
\hline No & 88 & 22 & & 89 & 21 & \\
\hline \multicolumn{7}{|l|}{ Complication } \\
\hline Yes & 0 & 7 & 0.001 & 1 & 6 & \multirow{2}{*}{0.001} \\
\hline No & 94 & 20 & & 94 & 20 & \\
\hline
\end{tabular}


the cost after LSG is leakage. Similar results have been obtained in the literature in this issue (17). The most important reason for the increase in the total cost of staple line leakages is expensive treatment costs. Leakage treatment may require the patient to apply a stent $\geq 1$ time. The applied stents are also expensive medical supplies. Because of the need for endoscopic procedures for stenting, there is a separate endoscopic approach cost apart from the stent material cost. In addition to the stent applications, the abscess and collections that are formed in the abdomen should be drained during the management of the leakages. This drainage is usually percutaneously performed by the interventional radiology unit. The cost of the catheter used for drainage and the service cost of the application influence total cost increase. Intra-abdominal and respiratory system infections may also appear along with the staple line leakages. A broad spectrum and expensive antibiotics should be used for a long time in the treatment of these infections. This may also be one of the reasons for the increase in cost due to the presence of complications.

The other parameter that increased the cost was the length of hospitalization. It can be concluded that the complications developing during LSG operations are already considered to extend the length of hospitalization and that these two parameters are actually dependent parameters. Because of the possible mortal results of the complicatins, the complicated patients must be treated in the hospital, and the clinical conditions of the patients should be simultaneously monitored in the hospital. The use of medicines for treatment, the use of laboratory examinations and imaging modalities to assess the clinical status of the patient, and the effectiveness of treatment can be cited as the reasons for the increased cost of the long hospital stay.

In this study, the demographic parameters such as sex, age, and BMI did not affect the costs. In some studies, it is stated that with an increase in age, there are more comorbidities in the patients, which increase the incidence of the complications and indirectly increase the costs. There are studies in the literature that suggest that BMI is a parameter that affects the development of complications. In these studies, it is stated that a higher BMI is associated with higher complication rates and costs (20-22). Despite the fact that all the patients who were operated on in this study were morbidly obese with $>40 \mathrm{~kg} / \mathrm{m}^{2} \mathrm{BMI}$, no relation was found between cost increase and BMI.

When the cost and invoice amounts for LSG were examines, the average cost was $3633.5 \mathrm{TL}$, and the average invoiced amount was 6095.7 TL. It would not be ethical to consider this difference as the hospital's profit because employee salary expenses and the costs of hospitalization were not included in the total cost. This can be considered as a limitation of the study. However, it is possible that hospitals would not suffer but would rather profit from the LSG surgery when the estimated employee salary expenses and the estimated costs of hospitalization were added to the total costs. If the amount invoiced is considered as a cost for SII, the positive effects provided by the LSG surgery are much higher than the average invoice amount of 6095.7 TL because an effective weight loss of these patients will result in an increase in workforce performance, and a reduction in the severity of obesity-related systemic diseases will reduce the costs of treat- ing these diseases. The financial profit of these results is much more than this amount. Furthermore, the location of our study may be the reason for the limitation. In public hospitals, profiting is not the primary goal. Therefore, the amounts provided in our study may vary in private hospitals. This can also be considered a limitation of the study.

\section{CONCLUSION}

It can be considered that LSG is an effective and a cost-effective procedure in the surgical treatment of obesity. The most important parameters for increasing the costs are the development of complication and the length of hospitalization. Patients' age, sex, $\mathrm{BMI}$, and the postoperative need of ICU care do not increase the cost of surgery. The cost increase in LSG surgery is unpredictable because it is not associated with the patient's variables. There is a need for further studies that would examine the variables involved in surgical intervention.

Ethics Committee Approval: Author declared that the research was conducted according to the principles of the World Medical Association Declaration of Helsinki "Ethical Principles for Medical Research Involving Human Subjects", (amended in October 2013).

Informed Consent: Due to the retrospective design of the study, informed consent was not taken

Peer-review: Externally peer-reviewed.

Conflict of Interest: The author has no conflicts of interest to declare.

Financial Disclosure: The author declared that this study has received no financial support.

\section{REFERENCES}

1. Brethauer SA. Sleeve Gastrectomy. Surg Clin N Am 2011; 91: 126579. [CrossRef]

2. Buchwald H, Oien DM. Metabolic/bariatric surgery worldwide 2008. Obes Surg 2009; 19: 1605-11. [CrossRef]

3. Dixon JB, Zimmet P, Alberti KG, Rubino F. Bariatric surgery: an IDF statement for obese type 2 diabetes. Diabet Med 2011; 28: 628-42. [CrossRef]

4. Khuri SF, Najjar SF, Daley J, Krasnicka B, Hossain M, Henderson WG, et al. VA National Surgical Quality Improvement Program. Comparison ofsurgical outcomes between teaching and non-teachinghospitals in the Department of Veterans Affairs. Ann Surg 2001; 234: 37082. [CrossRef]

5. Dixon JB, le Roux CW, Rubino F, Zimmet P. Bariatric surgery for type 2 diabetes. Lancet 2012; 379: 2300-11. [CrossRef]

6. Buchwald H, Oien DM. Metabolic/bariatric surgery worldwide 2011. Obes Surg 2013; 23: 427-36. [CrossRef]

7. Khorgami Z, Aminian A, Shoar S, Andalib A, Saber AA, Schauer $P R$, et al. Cost of bariatric surgery and factors associated with increased cost: an analysis of national inpatient sample. Surg Obes Relat Dis 2017; 13: 1284-9. [CrossRef]

8. Alsumali A, Eguale T, Bairdain S, Samnaliev M. Cost-Effectiveness Analysis of Bariatric Surgery for Morbid Obesity. Obes Surg 2018 doi: 10.1007/s11695-017-3100-0. [Epub ahead of print] [CrossRef]

9. Larsen, Edward R (Feb 1988); "Systems Support Cost Accounting and Quality Of Care", Healthcare Financial Management; 42, 2; ABI/ INFORM Global ss. 86-88

10. Bulut, Dilek (2004); İsman, Çağla; "Muğla illi Sağlık Yöneticilerinde Kişisel Değer Analizi" , Hacettepe Sağlık Idaresi Dergisi, Cilt:7, Sayı:3, 278- 293. 
11. Tutar F, Kılınç N. "Türkiye'nin Sağlık Sektöründeki Ekonomik Gelişmiş̧lik Potansiyeli ve Farklı Ülke Örnekleriyle Mukayesesi" Afyon Kocatepe Üniversitesi, i.i.B.F. Dergisi 2007, C.IX, Sayı:1, s.31-54.

12. Dawson D, Goddard M, Street A. "Improving Performance in Public Hospitals: a Role For Comparative Costs?" Health Policy 2001, 57, s.235-48. [CrossRef]

13. Yiğit V, Ağırbaş I. Hastane Iş̧letmelerinde Kapasite Kullanım Oranının Maliyetlere Etkisi: Sağlık Bakanlığı Tokat Doğum ve Çocuk Bakımevi Hastanesinde Bir Uygulama. Hacettepe Sağlık Idaresi Dergisi, 2004, Cilt:7, Sayı:2, s.141-62.

14. Minh HV, Giang KB, Huong DL, Le TH, Nguyen TH, Pham NG, et al. Costing of Clinical Services in Rural District Hospitals in Northern Vietnam. The International Journal of Health Planning and Management 2010; 25: 63-73.

15. von Elm E, Altman DG, Egger M, Pocock SJ, Gøtzsche PC, Vandenbroucke JP, et al. The Strengthening the Reporting of Observational Studies in Epidemiology (STROBE) Statement: guidelines for reporting observational studies. Int J Surg 2014; 12: 1495-9. [CrossRef]

16. Flego A, Keating C, Moodie M. Cost-effectiveness of whole-ofcommunity obesity prevention programs: an overview of the evidence. Expert Rev Pharmacoecon Outcomes Res 2014; 14: 719-27. [CrossRef]
17. Picot J, Jones J, Colquitt JL, Gospodarevskaya E, Loveman E, Baxter $L$, et al. The clinical effectiveness and cost-effectiveness of bariatric (weight loss) surgery for obesity: a systematic review and economic evaluation. Health Technol Assess 2009; 13: 1-190. [CrossRef]

18. Wang BC, Wong ES, Alfonso-Cristancho R, He H, Flum DR, Arterburn $D E$, et al. Cost-effectiveness of bariatric surgical procedures for the treatment of severe obesity. Eur J Health Econ 2014; 15: 25363. [CrossRef]

19. Nguyen NT, Okrainec A, Anvari M, Smith B, Meireles O, Gee D, et al. Sleeve gastrectomy telementoring: a SAGES multi-institutional quality improvement initiative. Surg Endosc 2018; 32: 682-7. [CrossRef]

20. van Rutte PW, Smulders JF, de Zoete JP, Nienhuijs SW. Sleeve gastrectomy in older obese patients. Surg Endosc 2013; 27: 2014-9. [CrossRef]

21. Mizrahi I, Alkurd A, Ghanem M, Zugayar D, Mazeh H, Eid A, et al. Outcomes of laparoscopic sleeve gastrectomy in patients older than 60 years. Obes Surg 2014; 24: 855-60. [CrossRef]

22. Fischer $\mathrm{L}$, Wekerle $\mathrm{AL}$, Bruckner $\mathrm{T}$, Wegener I, Diener MK, Frankenberg MV, et al. BariSurg trial: Sleeve gastrectomy versus Roux-en-Y gastric bypass in obese patients with BMI $35-60 \mathrm{~kg} / \mathrm{m}(2)$ - a multicentre randomized patient and observer blind non-inferiority trial. BMC Surg 2015; 15: 87. [CrossRef] 